\title{
Catches of bloodsucking blackflies (Diptera: Simuliidae) tell different stories depending on sampling method
}

\author{
Björn Malmqvist, Darius Strasevicius \& Peter H. Adler
}

\begin{abstract}
Malmqvist, B., Strasevicius, D. \& Adler, P. H. 2007: Catches of bloodsucking blackflies (Diptera: Simuliidae) tell different stories depending on sampling method. - Entomol. Fennica 18: 110-116.
\end{abstract}

To compare different sampling techniques, blackflies were captured along six Swedish rivers in 2001 and 2002, using two fundamentally different methods: (1) daytime trapping with a vehicle-mounted net, and (2) exposure of $\mathrm{CO}_{2}$-baited traps. The methods were selectively different for different species of blackflies. Some species were caught relatively more frequently by vehicle trapping and others by $\mathrm{CO}_{2}$ trapping. Only rarely were species catches proportionally similar between the two methods. We suggest that the different catch success reflects differences in host-searching behaviour in the species present and that the sampling methods are complementary.

Björn Malmqvist, Department of Ecology and Environmental Science, Umeå University, SE-90187 Umeå, Sweden; E-mail: bjorn.malmqvist@emg.umu.se Darius Strasevicius, Department of Ecology and Environmental Science, Umeå University,SE-90187Umeå, Sweden; E-mail: darius.strasevicius@emg.umu.se Peter H. Adler, Clemson University, Department of Entomology, Soils, and Plant Sciences, 114 Long Hall, Clemson SC 29634, USA; E-mail: padler@clemson.edu

Received 21 March 2006, accepted 22 August 2006

\section{Introduction}

Blackflies are haematophagous parasites and vectors of apicomplexans, bacteria, filarial nematodes, flagellates, and viruses (Adler et al. 2004). Apart from their role as vectors of the filarial agents that cause onchocerciasis (river blindness), a widespread and serious disease in humans (Crosskey 1990), much of their capacity as vectors is poorly known. Females of most species of blackflies require blood for egg development. Their hosts are endothermic, and blackfly species are either mammalophilic or ornithophilic (Crosskey 1990, Malmqvist et al. 2004b). Blackflies, after emergence, show an ordered sequence of activities from mating, sugar feeding, host location, blood feeding, egg maturation, to the return to flowing water for oviposition, sometimes repeated in multiple cycles (Sutcliffe 1986). Hosts are located by means of olfactory and, at closer range, visual and possibly thermal cues (Sutcliffe 1986). To the hosts, blackfly attacks cause distress, blood loss, and parasite transmission, and during mass attacks, anaphylactic shock and other malicious effects (Crosskey 1990).

Quantitative methods are crucial to understanding the ecological roles of black flies in the terrestrial landscape and to improving control of deleterious species. However, no universal sampling method exists, and quantifying them is ei- 
ther done by making direct counts on hosts, e.g. exposed humans, domestic animals (e.g. Anderson \& Yee 1995), or captive wild animals (Anderson \& DeFoliart 1961, Ojanen et al. 2004). They are also caught overhead with standardised net sweeps (Gray et al. 1996) or attracted using carbon dioxide baited traps that can be spiked with additional attractants or modelled to the likeness of a potential host (Helle et al. 1992, Martin et al. 1994, Anderson et al. 2001). Other methods are passive and involve the collection of flying insects with vehicle-mounted nets (e.g. Davies \& Roberts 1980) or suction traps without attractants (Choe et al. 1984).

Our previous work on blackflies in northern Sweden has demonstrated large interspecific differences in breeding habitats (Malmqvist et al. 1999) and host choice (Malmqvist et al. 2004b). For instance, the larvae of certain species develop uniquely in large rivers originating in the mountain region in the borderland between Norway and Sweden, whereas those of other species are confined to small or even tiny streams, depending on morphological constraints in the head fans used for capturing food particles from the water current (Zhang \& Malmqvist 1996). Females dispersing from large rivers may travel relatively long distances in search of hosts (e.g. Garms \& Walsh 1987). To achieve a distribution corresponding to species developing in widely separated, large rivers, blood-seeking females emerging from local stream networks can be expected to show movement patterns that are comparatively more spatially restricted. We have made considerable efforts to sample flying blackflies, using vehicle-mounted nets, but preliminary testing of attractant traps suggested that these nets might give a different picture of the blackfly assemblages present. Here we examine, concomitantly using vehicle-mounted traps and $\mathrm{CO}_{2}-$ baited traps, to what extent the hunting mode, as expressed in flying and attraction, respectively, differs with respect to species and host type.

\section{Material and methods}

The investigation was performed at sites along six of the main rivers in northern Sweden in the summers of 2001 and 2002. The study area is lo-
Table 1. Description of river sites. Rivers are arranged from south to north. Damming and associated habitat destruction is extensive in regulated rivers (' $R$ '), whereas free-flowing rivers ('F') have intact larval habitats. Sampling was carried out on the same dates in river pairs.

\begin{tabular}{|c|c|c|c|}
\hline Rivers & Coordinates & Regulation & $\begin{array}{l}\text { Elevation } \\
\text { (m a.s.I.) }\end{array}$ \\
\hline \multicolumn{4}{|c|}{ 14-15. and 26-27.VI.2001, 1-2.VII.2002 } \\
\hline Ume & $\begin{array}{l}64^{\circ} 03^{\prime} 16^{\prime \prime} \mathrm{N} \\
19^{\circ} 36^{\prime} 29^{\prime \prime} \mathrm{E}\end{array}$ & $\mathrm{R}$ & 179 \\
\hline Vindel & $\begin{array}{l}64^{\circ} 00^{\prime} 54^{\prime \prime} \mathrm{N} \\
19^{\circ} 56^{\prime} 14^{\prime \prime} \mathrm{E}\end{array}$ & $\mathrm{F}$ & 155 \\
\hline \multicolumn{4}{|c|}{ 19-20.VI. and 2-3.VII.2001, 11-12.VII.2002 } \\
\hline Skellefte & $\begin{array}{l}65^{\circ} 06^{\prime} 25^{\prime \prime} \mathrm{N} \\
19^{\circ} 25^{\prime} 45^{\prime \prime} \mathrm{E}\end{array}$ & $\mathrm{R}$ & 247 \\
\hline Pite & $\begin{array}{l}65^{\circ} 57^{\prime} 02^{\prime \prime} \mathrm{N} \\
19^{\circ} 33^{\prime} 49^{\prime \prime} \mathrm{E}\end{array}$ & $\mathrm{F}$ & 270 \\
\hline \multicolumn{4}{|c|}{ 21-22.VI. and 4-5.VII.2001, 7-8.VIII.2002 } \\
\hline Lule & $\begin{array}{l}65^{\circ} 44^{\prime} 17^{\prime \prime} \mathrm{N}(2001) \\
24^{\circ} 43^{\prime} 322^{\prime \prime} \mathrm{E} \\
66^{\circ} 04^{\prime} 42^{\prime \prime} \mathrm{N}(2002) \\
20^{\circ} 56^{\prime} 36^{\prime \prime} \mathrm{E}\end{array}$ & ) $R$ & $\begin{array}{l}54 \\
19\end{array}$ \\
\hline Kalix & $\begin{array}{l}66^{\circ} 37^{\prime} 27^{\prime \prime} \mathrm{N}(2001) \\
22^{\circ} 46^{\prime} 15^{\prime \prime} \mathrm{E} \\
65^{\circ} 59^{\prime} 51^{\prime \prime} \mathrm{N}(2002) \\
22^{\circ} 56^{\prime} 04^{\prime \prime} \mathrm{E}\end{array}$ & ) & $\begin{array}{r}117 \\
47\end{array}$ \\
\hline
\end{tabular}

cated in the taiga, with catchments primarily covered by Norwegian spruce and Scots pine forests, although also including areas with farmland, mire and clear-cut forest in the investigation area. Trapping took place about $1 \mathrm{~km}$ from the nearest large rivers. The rivers sampled represent pairs, whereby one river in each pair is regulated for hydropower purposes and the other is free flowing (Table 1). The comparison with respect to river regulation will be presented elsewhere.

At each site, we used nine $\mathrm{CO}_{2}$-baited traps of CDC type (Centers for Disease Control and Prevention, USA; manufacturer: Machine Works, Toms River, New Jersey) modified by replacing the traditional live-catch mosquito fabric cage unit by a funnel-shaped fine-mesh net with a tube containing $70 \%$ ethanol attached to its base and light bulbs removed. Each trap was supplied with ca $1 \mathrm{~kg}$ of dry ice as a source of carbon dioxide fastened under the top of the trap. The dry ice was 
Table 2. Mean proportion (across rivers) of species representation in $\mathrm{CO}_{2}$ and vehicle traps, respectively, in the 2001 data set (two seasons combined). Multiple species names are indicated in cases where species could not be separated.

\begin{tabular}{|c|c|c|c|c|c|}
\hline \multirow[t]{2}{*}{ Species } & \multirow{2}{*}{$\begin{array}{l}\text { Primary } \\
\text { host }^{1}\end{array}$} & \multirow{2}{*}{$\begin{array}{l}\text { Breeding } \\
\text { habitat }^{2}\end{array}$} & \multirow{2}{*}{$\begin{array}{l}\text { Rivers with } \\
\text { species } \\
\text { recorded }(\mathrm{N})\end{array}$} & \multicolumn{2}{|c|}{ Proportion of catch } \\
\hline & & & & $\mathrm{CO}_{2}$ trap & Vehicle trap \\
\hline Prosimulium hirtipes & M & S-L & 1 & 0 & 0.016 \\
\hline Stegopterna trigonium & M & S & 2 & 0.010 & 0 \\
\hline Metacnephia lyra & B & L & 6 & 0.165 & 0.527 \\
\hline M. saileri & B & $\mathrm{V}$ & 2 & $<0.001$ & 0.014 \\
\hline Simulium annulus & B & L & 3 & $<0.001$ & 0.170 \\
\hline $\begin{array}{l}\text { S. bicorne, carpathicum, } \\
\text { cryophilum, urbanum, } \\
\text { vernum }\end{array}$ & B & $\mathrm{S}$ & 4 & 0.007 & 0.010 \\
\hline S. equinum & M & M & 2 & 0.001 & 0.040 \\
\hline S. erythrocephalum & M & M-L & 1 & 0.053 & 0.120 \\
\hline S. intermedium & M & V & 1 & 0.004 & 0 \\
\hline S. Iundstromi & B & $\mathrm{s}$ & 3 & 0.040 & 0.003 \\
\hline S. murmanum & M & L & 4 & 0.061 & 0.067 \\
\hline S. ornatum & M & $\mathrm{V}$ & 5 & 0.047 & 0.001 \\
\hline S. pusillum, subpusillum & M & $\mathrm{L}$ & 3 & 0.020 & 0.010 \\
\hline S. rostratum & M & $M-L$ & 4 & 0.023 & 0 \\
\hline $\begin{array}{l}\text { S. rubtzovi, curvistylus, } \\
\text { morsitans }\end{array}$ & M & $M-L$ & 6 & 0.028 & 0.010 \\
\hline S. silvestre, curvans & B & $\mathrm{s}$ & 5 & 0.179 & 0.006 \\
\hline $\begin{array}{l}\text { S. truncatum, paramorsitans } \\
\text { posticatum }\end{array}$ & $M$ & $M-L$ & 6 & 0.348 & 0.153 \\
\hline S. transiens & B & L & 2 & 0.033 & 0.003 \\
\hline S. tuberosum, vulgare & $\mathrm{M}$ & S-L & 6 & 0.140 & 0.086 \\
\hline S. usovae/rendalense & $\mathrm{B}$ & $S$ & 1 & 0.001 & 0 \\
\hline
\end{tabular}

$1 \mathrm{~B}=$ Birds; $\mathrm{M}=$ Mammals.

$2 \mathrm{~L}=$ Large rivers; $\mathrm{M}=$ Medium-sized rivers; $\mathrm{S}=$ Streams; $\mathrm{V}=$ Variable breeding habitats.

wrapped in several layers of newspapers and the release rate was ca $400 \mathrm{ml} \mathrm{CO} / \mathrm{min}$. The traps were distributed along a distance of $3-5 \mathrm{~km}$ and located ca $1 \mathrm{~m}$ (range $0.5-1.5$ ) above the ground, i.e. operating approximately at the same height as the vehicle trap. Exposure time was about 20 hours. All sampling was carried out under good weather conditions, i.e. at temperatures $\geq 12^{\circ} \mathrm{C}$, with no or only weak winds on precipitation-free days.

A car with a net mounted on the roof (Malmqvist et al. 2004b) was operated twice at $40 \mathrm{~km} \mathrm{~h}^{-1}$ over the same 3-5 km stretch along which the $\mathrm{CO}_{2}$ traps were deployed. Sampling was carried out approximately between noon and 10 a.m. the next day. Samples were labelled and stored in $70 \%$ ethanol until identification in the laboratory. Species were identified using a key modified from Adler et al. (2004). Only females were considered; however, gravid and engorged individuals were excluded, thus focussing on host-seeking blackflies. Females of certain species are presently inseparable (see Table 2). Only the material from 2001 was identified to the species level.

Analytical methods included Chi-square tests that were used to assess probability values for the relationship between two dichotomous variables, such as the efficiency of two sampling methods in capturing insects derived from two habitat types (large and small rivers), host categories (birds and mammals) and phylogenetic groups (Simulium vs. non-Simulium genera, i.e. Prosimulium, $\mathrm{Me}$ tacnephia, and Stegopterna). Pearson bivariate correlation was used to relate catches between the two sampling methods in the two years. 

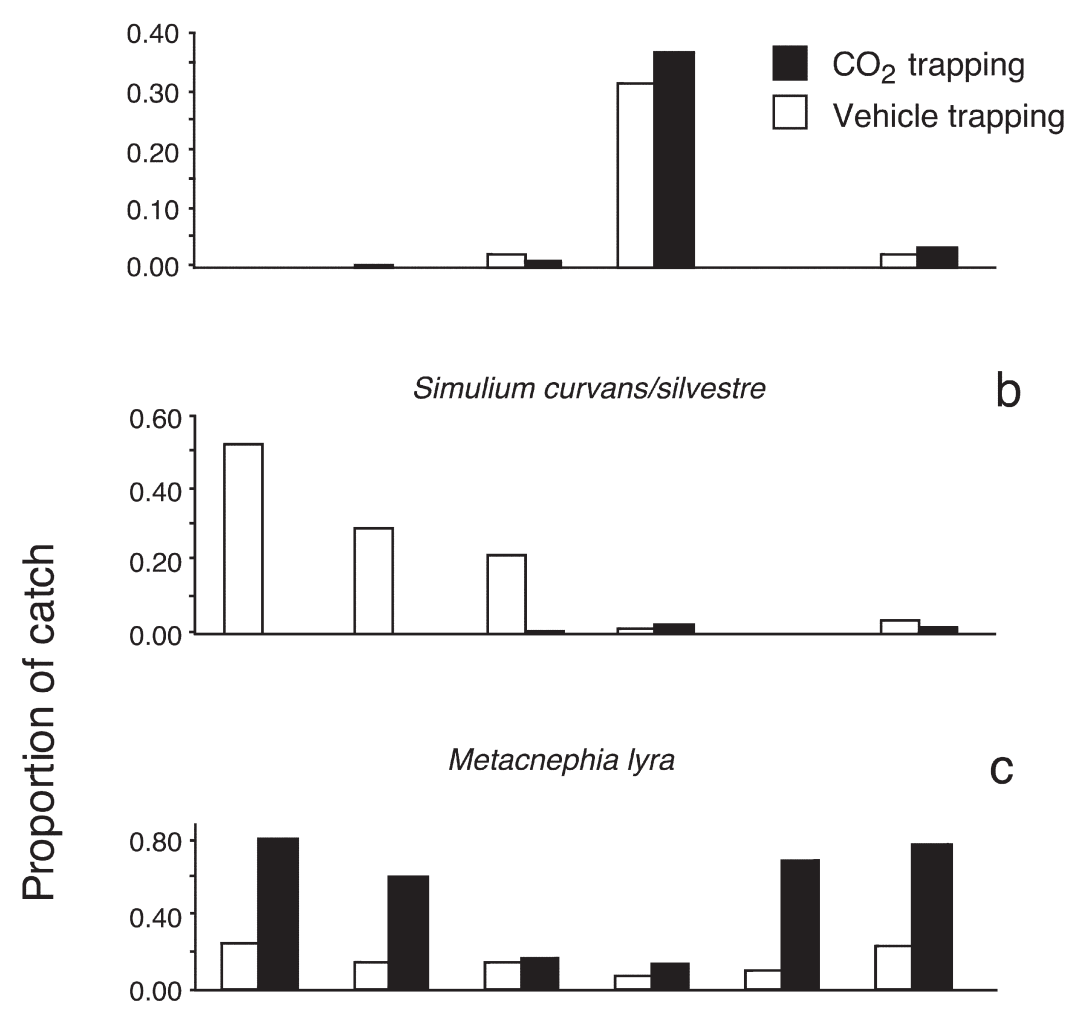

Fig. 1. Proportions of species relative to entire blackfly catches, using $\mathrm{CO}_{2}$ and vehicle trapping. Panel a) indicates equal success for the two methods, b) that $\mathrm{CO}_{2}$ trapping was more efficient than vehicle trapping, c) that vehicle trapping was more efficient than $\mathrm{CO}_{2}$, and d) that there was an unexplained pattern.

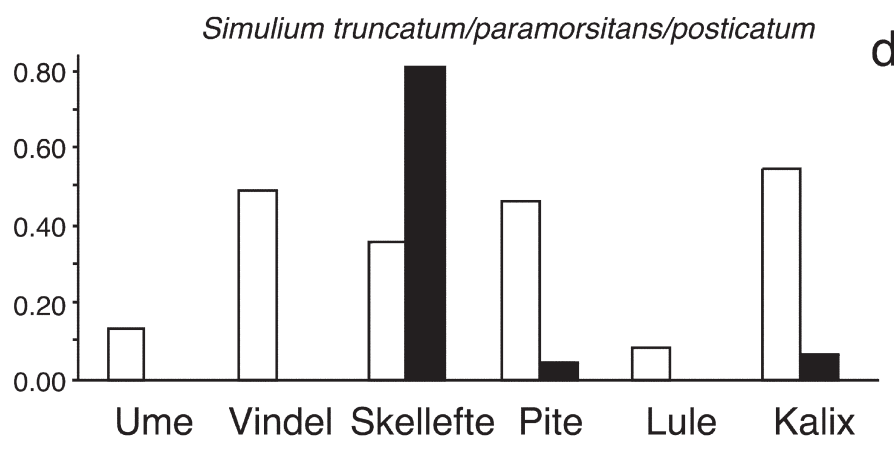

River

\section{Results}

$\mathrm{CO}_{2}$ traps almost exclusively collected females of blackflies, mosquitoes (Culicidae) and biting midges (Ceratopogonidae). The traps yielded in total 8,471 and 6,507 blackflies (all females) in June and July 2001, respectively, and 25,913 in $\mathrm{b}$ C d the single season (July/August) of 2002 (Table 1). The largest number caught in a single trap, 10,773 blackfly females, was recorded on the Pite River 11-12.VII.2002. Vehicle trapping yielded much lower numbers: 196 and 450, respectively, in 2001, and 227 in 2002, and these numbers represent a mixture of males and females (Table 2). Fe- 
males made up, on average, 76.7 and $77.6 \%$ of the vehicle-trap catches in the first and second round in 2001, respectively, but only $46.3 \%$ in the 2002 sampling. Small numbers of gravid (5) or engorged (1) females were captured but not included in analyses.

The relative catch statistics pertaining to the two methods of sampling showed four types of relationships. First, as in Simulium murmanum, the proportional representation was nearly identical for the two methods (Fig. 1a). Second, the $\mathrm{CO}_{2}$ traps were highly efficient for $\mathrm{S}$. silvestre/curvans, whereas vehicle trapping was not (Fig. 1b). A decreasing trend toward the north is also evident in this blackfly group. Thirdly, vehicle trapping was relatively more efficient than $\mathrm{CO}_{2}$ trapping for Metacnephia lyra (Fig. 1c), and lastly, in some species, there was inconsistent variation; $S$. truncatum/paramorsitans/posticatum, for example, showed a high vehicle-trap catch in one instance (Skellefte River) but was, despite presence in $\mathrm{CO}_{2}$ traps, rare or absent in vehicle-trap catches on all other river sites (Fig. 1d). Examining additional species (Table 2) yielded several other examples where $\mathrm{CO}_{2}$ trapping appeared more efficient than vehicle trapping (S. ornatum, S. lundstromi, S. rostratum, and S. transiens) or vice versa (Metacnephia salieri, S. annulus, S. erythrocephalum, and Prosimulium hirtipes). Variable success was found in the $S$. venustum group, $S$. vernum group, S. pusillum/ subpusillum, and in S. equinum.

Slightly more species (19) were captured by $\mathrm{CO}_{2}$ trapping than by vehicle trapping (16). This small difference remained when host type (birds vs. mammals) was considered $\left(\mathrm{CO}_{2}: 8\right.$ ornithophilic species, 11 mammalophilic species; vehicle: 7 ornithophilic species, 9 mammalophilic species; Chi-square $=0.01 ; p>0.05$ ). Neither were non-Simulium species captured more frequently by any of the methods (Chi-square = $0.05 ; p>0.05)$. River-size origin also did not matter (Chi-square $=0.28 ; p>0.05)$.

In contrast to the analyses of species numbers, those considering abundances showed strong effects of sampling method. The analysis of largeriver vs. small-stream species demonstrated that $\mathrm{CO}_{2}$ trapping captured relatively higher numbers of small-stream derived females $(10 \%$ of catch) than did vehicle trapping ( $3 \%$ of catch) (Chi- square $=23.69 ; p<0.001) . \mathrm{CO}_{2}$ trapping also captured relatively more females of mammalophilic species $(60 \%)$ than did vehicle trapping $(53 \%)($ Chi-square $=12.68 ; p<0.001)$. Finally, vehicle trapping ( $45 \%$ of catch) was more efficient relative to $\mathrm{CO}_{2}$ trapping (35\% of catch) (Chi-square $=23.41 ; p<0.001)$ in catching nonSimulium females, suggesting a phylogenetic effect of the sampling method as well.

Comparing catches, using the two methods, resulted in correlations that varied in strength (July 2001 data: $r=0.638, p>0.05$; July 2001 data: $r=0.950, p<0.005 ; 2002$ data: $r=0.589, p$ $>0.05)($ all df=4).

\section{Discussion}

The variability in capture success among different species is intriguing. Our observations suggest that blackfly females use at least two search modes for detecting a host: (1) sit-and-wait, whereby the fly probably waits inactively in the vegetation for a cue to begin host pursuit, which could include $\mathrm{CO}_{2}$ or a visual stimulus (e.g. colour, shape), or (2) active search, again probably involving $\mathrm{CO}_{2}$, although visual cues cannot be ruled out. These findings support the contention that blackflies either roam in search of hosts or sit and wait until a host comes near enough to be detected (Simmons 1985).

However, $\mathrm{CO}_{2}$-baited traps sample females engaged only in host seeking, which represents a subset of the behaviours of females collected by vehicle traps. Females taken in vehicle traps could be engaged not only in host seeking, but also in dispersal flights, searches for sugar meals and resting sites, and mating encounters with males. The proportions of females in the two types of traps, therefore, might reflect differences in the frequencies of the various behaviours at the times of collection.

Discrepancies between the outcomes of the different methods also might indicate that species of blackflies differ in diurnal activity. Some species would be active at the time when vehicle trapping is performed (afternoon), which would yield catches using both $\mathrm{CO}_{2}$ and vehicle-trapping methods, whereas such species that have early-morning or late-evening activity peaks 
would avoid being caught and hence produce relatively lower vehicle-trapping catches. Moreover, higher vehicle-trapping success relative to $\mathrm{CO}_{2}$ trapping would suggest that the blackflies rely more on visual than chemical cues. However, our night-time vehicle trapping has generally showed little activity. Instead, females tend to show peak activity in late morning (10.30) and early night (19.30), with few females being active between 21.00 and 09.00 (Strasevicius \& Malmqvist, unpubl.), and then mainly those of Simulium tuberosum/vulgare, a rodent specialist (Malmqvist et al. 2004b). Low capture success, using vehicle trapping, could potentially also be the case if females fly high above the ground, as reported for the $S$. aureum species complex (2-8 $m$ above ground) (Bennett 1960), or very close to the ground, as in S. rugglesi (Smith 1966).

The difficulties in separating the females in certain groups could have contributed to some of the variation in the catches if such groups contain species with contrasting hunting modes. For example, females of the indistinguishable species Simulium truncatum, S. posticatum, and S. paramorsitans might have different diel activity patterns (e.g. with one or two species not flying in the afternoon) and different representation across the study region, which potentially could result in patterns generating inconsistencies between $\mathrm{CO}_{2}$ and vehicle trapping (cf. Fig. 1C).

The higher species number observed for $\mathrm{CO}_{2}$ trapping is likely to be a result of the higher number of individuals captured because species richness is dependent on numbers (Gotelli \& Colwell 2001). We found no selectivity by either method on how many species of bird vs. mammal specialists were captured. Likewise, there was no such selectivity concerning the main phylogenetic groups, i.e. Simulium vs. non-Simulium genera, or river origin. In contrast, the analyses of abundances indicated that small-stream species were represented in larger proportion in the $\mathrm{CO}_{2}$ trap catches, suggesting that these, in accordance with our predictions, better reflected locally produced blackflies. Although many small-stream species are ornithophilic, this tendency did not show in the catches, where mammalophilic species still were better represented in $\mathrm{CO}_{2}$ traps than in vehicle traps, which was partly due to the abundant, large-river dominant species Metacnephia lyra.
Our study shows that relying on a single sampling approach might carry risks. In our opinion, there are arrays of different blackfly assemblages invading the terrestrial landscape, depending on the regional availability and quality of stream habitats, which together with the female behaviour (widely searching or sit-and-wait) of different species, govern their distribution across these landscapes. To assess populations with high accuracy is probably not possible with the methods presently available. However, vehicle-mounted traps should provide a reasonably standardised measure but with an under-representation of certain species, whereas if attractant traps are the sole method used, a high yield per effort of blackflies would be obtained but again with a skewed species representation.

A particular advantage of vehicle trapping is that males will be caught, which favours correct identification, even if not in all cases to the species level. Although $\mathrm{CO}_{2}$ trapping provides high numbers of blackflies, it has the drawbacks of an absence of males and the need for two visits if deployed overnight. $\mathrm{CO}_{2}$ traps would also not capture obligately autogenous (i.e. non-bloodsucking) species, which represent some ten per cent of the species in northern Sweden (Adler et al. 1998).

Blackflies are highly important members of the boreal ecosystem, with many likely but unexplored influences in the aquatic as well as in the terrestrial environments (Adler \& Malmqvist 2004, Malmqvist et al. 2004a). This contention still needs more specifications to better determine their various impacts. For some of the most important impacts, such as biting and disease transmission, efficient methods of quantification are required. On the aspect of host-location behaviour we need better information on flight height and diel activity. To our knowledge, there is no such information for European species. Other future needs include the ability to track the origin of captured species and to map their subsequent dispersal patterns, which would enable effective control if deemed necessary. We stress that in all this work, blackflies must be recognized as a composite group of insects showing multiple strategies with respect to habitats, behavioural patterns, and hosts, for which study methods might vary depending on which species is in fo- 
cus. More general studies should preferably employ a combination of sampling techniques.

Acknowledgements. We thank Karl Malmqvist for his careful assistance with the processing of the blackfly samples.

\section{References}

Adler, P. H. \& Malmqvist, B. 2004: Predation on black flies (Diptera: Simuliidae) by the carnivorous plant Pinguicula vulgaris (Lentibulariaceae) in northern Sweden. - Entomol. Fennica 15: 124-128.

Adler, P. H., Malmqvist, B. \& Zhang, Y. 1998: Black flies (Diptera: Simuliidae) of northern Sweden: taxonomy, chromosomes, and bionomics. — Entomol. Scand. 29: 361-382.

Adler, P. H., Currie, D. C. \& Wood, D. M. 2004: The black flies (Simuliidae) of North America. - Cornell University Press, Ithaca, New York. 941 pp.

Anderson, J. R. \& DeFoliart, G. R. 1961: Feeding behavior and host preferences of some black flies (Diptera: Simuliidae) in Wisconsin. - Ann. Entomol. Soc. Am. 54: 716-729.

Anderson, J. R. \& Yee, W. L. 1995: Trapping black flies (Diptera-Simuliidae) in northern California.I. Species composition and seasonal abundance on horses, host models, and in insect flight traps. - J. Vector Ecol. 20: $7-25$.

Anderson, J. R., Nilssen, A. C. \& Hemmingsen, W. 2001: Use of host-mimicking trap catches to determine which parasitic flies attack reindeer, Rangifer taran$d u s$, under different climatic conditions. - Can. FieldNat. 115: 274-286.

Bennett, G. F. 1960. On some ornithophilic blood-sucking Diptera in Algonquin Park, Ontario, Canada. - Can. J. Zool. 38: 377-389.

Choe, J. C., Adler, P. H., Kim, K. C. \& Taylor, R. A. J. 1984: Flight patterns of Simulium jenningsi (Diptera: Simuliidae) in central Pennsylvania, USA. - J. Med. Entomol. 21: 474-476.

Crosskey, R. W. 1990: The natural history of blackflies. John Wiley, Chichester. 711 pp.

Davies, L. \& Roberts. D. M. 1980: Flight activity of female black-flies (Diptera: Simuliidae) studied with a vehicle-mounted net in northern England. - J. Nat. Hist. 14: $1-16$.

Garms, R. \& Walsh, J. F. 1987: The migration and dispersal of black flies: Simulium damnosum s.1., the main vector of human onchocerciasis. - In: Kim K. C. \&
Merritt, R. W. (eds.), Black flies. Ecology, population management and annotated world list: 201-214. Pennsylvania State University, University Park.

Gotelli, N. J., \& Colwell. R. K. 2001: Quantifying biodiversity: procedures and pitfalls in the measurement and comparison of species richness. - Ecol. Lett. 4: 379-391.

Gray, E. W., Adler, P. H. \& Noblet, R. 1996: Economic impact of black flies (Diptera: Simuliidae) in South Carolina and development of a localized suppression program. - J. Am. Mosq. Control Assoc. 12: 676678.

Helle, T., Aspi, J., Lempa, K. \& Taskinen, E. 1992: Strategies to avoid biting flies by reindeer - field experiments with silhouette traps. - Ann. Zool. Fennici 29: 69-74.

Malmqvist, B., Adler, P. H. \& Zhang, Y. 1999: Diversity, distribution, and larval habitats of North Swedish blackflies (Diptera: Simuliidae). — Freshwat. Biol. 42: 301-314.

Malmqvist, B., Adler, P. H., Kuusela, K., Merritt, R. W. \& Wotton, R. S. 2004a: Black flies in the boreal biome, key organisms in both terrestrial and aquatic environments: A review. - Ecoscience 11: 187-200.

Malmqvist, B., Strasevicius, D., Hellberg, O., Adler, P. H. and Bensch, S. 2004b: Vertebrate host specificity of wild-caught blackflies revealed by mitochondrial DNA in blood. - Proc. R. Soc. Lond., Ser. B: Biol. Sci. (Supplement), Biol. Lett. 271: S152-S155.

Martin, F. R., McCreadie, J. W. \& Colbo, M. H. 1994: Effect of trap site, time of day, and meteorological factors on abundance of host-seeking mammalophilic black flies (Diptera: Simuliidae). - Can. Entomol. 126: 283-289.

Ojanen, U., Rätti, O., Adler, P. H., Kuusela, K., Malmqvist, B. \& Helle, P. 2002: Blood feeding by black flies (Diptera: Simuliidae) on black grouse (Tetrao tetrix) in Finland. - Entomol. Fennica 13: 153-158.

Simmons, K. R. 1985: Reproductive ecology and hostseeking behavior of the black fly, Simulium venustum Say (Diptera: Simuliidae). - Ph. D. thesis. University of Massachusetts, Amherst, Massachusetts.

Smith, S. M. 1966: Observations on some mechanisms of host finding and host selection in the Simuliidae and Tabanidae (Diptera). - M. S. thesis. McMaster University, Hamilton, Ontario.

Sutcliffe, J. F. 1986: Black fly host location: a review. Can. J. Zool. 64: 1041-1053.

Zhang, Y. \& Malmqvist, B. 1996: Relationships between labral fan morphology and habitat in North Swedish blackfly larvae (Diptera: Simuliidae). — Biol. J. Linn. Soc. 59: 261-280. 